\title{
Laboratory Testing for Prescription Opioids
}

\author{
Michael C. Milone
}

Published online: 21 November 2012

(C) American College of Medical Toxicology 2012

\begin{abstract}
Opioid analgesic misuse has risen significantly over the past two decades, and these drugs now represent the most commonly abused class of prescription medications. They are a major cause of poisoning deaths in the USA exceeding heroin and cocaine. Laboratory testing plays a role in the detection of opioid misuse and the evaluation of patients with opioid intoxication. Laboratories use both immunoassay and chromatographic methods (e.g., liquid chromatography with mass spectrometry detection), often in combination, to yield high detection sensitivity and drug specificity. Testing methods for opioids originated in the workplace-testing arena and focused on detection of illicit heroin use. Analysis for a wide range of opioids is now required in the context of the prescription opioid epidemic. Testing methods have also been primarily based upon urine screening; however, methods for analyzing alternative samples such as saliva, sweat, and hair are available. Application of testing to monitor prescription opioid drug therapy is an increasingly important use of drug testing, and this area of testing introduces new interpretative challenges. In particular, drug metabolism may transform one clinically available opioid into another. The sensitivity of testing methods also varies considerably across the spectrum of opioid drugs. An understanding of opioid metabolism and method sensitivity towards different opioid drugs is therefore essential to effective use of these tests. Improved testing algorithms and more research into the effective use
\end{abstract}

\section{C. Milone}

Department of Pathology and Laboratory Medicine, Perelman

School of Medicine at the University of Pennsylvania,

Philadelphia, PA 19104, USA

M. C. Milone $(\square)$

Pathology and Laboratory Medicine,

Hospital of the University of Pennsylvania,

7.103 Founders Pavilion, 3400 Spruce Street,

Philadelphia, PA 19104, USA

e-mail: milone@mail.med.upenn.edu of drug testing in the clinical setting, particularly in pain medicine and substance abuse, are needed.

Keywords Opioids · Screening · Pain medicine . Substance abuse

\section{Introduction}

Chronic noncancer pain represents a major health problem worldwide [1]. Although the long-term consequences of treating chronic noncancer pain with opioid drugs are unclear, prescription opioid use has risen over the past decade in an effort to enhance the treatment of chronic pain $[2,3]$. Over the past decade, misuse of prescription opioid drugs has also skyrocketed [4]. The desire to provide adequate control of pain while avoiding opioid misuse leads to a significant dilemma for the health care provider. Methods for detecting misuse are therefore critical adjuncts to prescribing these drugs. Several tools have been developed to aid in the detection opioid misuse and abuse including question-based screening tools [5-9], prescription drug monitoring programs [10], and drug testing. Urine drug testing (UDT) has been widely advocated as a method for identifying the misuse and abuse of opioid drugs during chronic pain and substance abuse treatment [11], and it is also frequently used in other clinical settings to screen for aberrant drug use such as in patients with behavioral disorders and other clinical signs and symptoms that suggest drug intoxication. The correct interpretation of testing is also critical as it may be the foundation to treatment decisions, criminal prosecution (e.g., impaired driver), or organ transplant eligibility. This review will focus on opioid drug testing, which continues to evolve alongside the growth in opioid drug use. In particular, the importance of testing approaches and their impact on the interpretation of results in the clinical settings will be discussed. 


\section{Urine Screening for Opioids}

Traditional approaches to drug screening in clinical medicine have relied upon the approaches originally developed for the workplace. Although this review will focus on opioids, similar testing can be performed for a diversity of substances. In the traditional testing scheme, two tiers of testing are employed. The first tier aims to rapidly screen large numbers of specimens for opioids. The second tier of testing is generally performed using highly specific methods such as gas chromatography or liquid chromatography with mass spectrometry that serve to confirm the screening result. Confirmatory testing is mandated in the forensic and workplace setting, with the latter following the Substance Abuse and Mental Health Services Administration (SAMHSA) testing guidelines [12]. Since confirmatory results are not generally available the same day, and therefore less likely to influence clinical decision making, hospital laboratories performing urine drug testing solely for clinical purposes may not routinely perform this second tier of testing [13].

The initial screening step plays a pivotal role in any testing scheme. In workplace opioid testing, detection of illicit drug use is sought in a population with a generally low prevalence of opioid use [14]. In the clinical setting, the prevalence of drug exposure is much higher due to the preselection of patients for screening based upon clinical suspicion of drug exposure or prescription of the opioid drug [15]. The purpose of testing may also be different in the clinical setting where the goal is often to detect nonuse of a prescribed opioid drug that may indicate drug diversion, which is an important contributor to the ongoing prescription opioid drug epidemic. These differences in prevalence and testing goal have an important impact on the utility of testing [16]. The effectiveness of the test can theoretically be improved in the clinical setting through changes to the concentration cutoff used to define a positive or negative test. Most clinical laboratories still use the $300 \mathrm{ng} / \mathrm{mL}$ of morphine as the cutoff concentration for a positive opioid screen; however, the effectiveness of this cutoff concentration in the detection of intoxication or aberrant opioid use has not been rigorously evaluated in many clinical settings in which it is generally used. This threshold was also developed in adult populations and may not be appropriate for children who produce less concentrated urine [17]. Lower thresholds have been advocated in the pain medicine setting [18]. The federally mandated $2,000 \mathrm{ng} / \mathrm{mL}$ threshold used in workplace testing (discussed below) is probably not appropriate in most clinical settings.

The cutoff concentration has been given significantly more attention in the workplace setting. The medico-legal consequences of testing in the workplace encourage great attention towards control of false positive results. Commonly prescribed drugs such as fluoroquinolone antibiotics have been reported to produce false positive results in some opiate immunoassays [19]. While confirmatory testing can correct for these false positive immunoassay results, this comes at significant cost since the confirmatory testing is a highly labor-intensive process unlike automated immunoassay testing. It is therefore highly desirable to minimize false positive results. Prior to 1998 , the federally mandated SAMHSA cutoff concentration for confirmatory testing was a morphine concentration of $300 \mathrm{ng} / \mathrm{mL}$ [12]. In order to address the problem of natural morphine and codeine in poppy seed containing products leading to a "false" positive test for illicit drug use, the federal workplace testing guidelines raised the confirmatory morphine concentration threshold to $2,000 \mathrm{ng} / \mathrm{mL}$ [12]. In the context of heroin as the most significantly abused opioid drug in the 1980s and 1990s, this change in cutoff concentration was predicted to significantly improve the positive predictive value (i.e., reduce the number of false positive tests) without impacting the negative predictive value of screening [20]. However, the epidemiology of opioid abuse has changed, and testing guidelines will likely have to change as well to enhance detection of prescription opioids that now exceed heroin in abuse [21].

Although often misunderstood, screening tests for opioid drugs also do not detect all opioid drugs equally. Opiate immunoassays, which use an antigen (drug)/antibody interaction for detection [22], typically use morphine as a single calibrator drug to set the threshold for distinguishing a "positive" or "negative" test result. Due to the limited cross-reactivity of antibodies with the diversity of opioid drugs, urine specimens containing many drugs may escape detection by opiate immunoassays. Table 1 shows the reported degree of cross-reactivity between commonly prescribed opioid drugs in a few of the opiate immunoassays used in clinical laboratories. The widely prescribed and abused opioid, oxycodone, illustrates this analytical pitfall well. Due to the structural differences between oxycodone and morphine shown in Fig. 1, oxycodone exhibits reduced affinity for the antibodies used in most commercial opiate screening assays. A greater than 6 -fold higher concentration of oxycodone is therefore required to achieve a positive screening result in many opiate immunoassays compared with morphine. Several studies have confirmed the low detection efficiency of morphine-specific opiate immunoassays for oxycodone [23-25]. Immunoassays that show higher specificity for oxycodone are available, and many labs (including the author's) utilize an oxycodone-specific (and also oxymorphone-specific) immunoassay in conjunction with a morphine-specific opiate immunoassay to maximize detection of prescription opioids [26]. Other prescription opioid drugs such as fentanyl and buprenorphine are sufficiently distinct in structure compared to morphine that these drugs show essentially no reactivity in commonly marketed morphine-specific opiate immunoassays (Fig. 1). 
Detection of these opioid drugs therefore requires entirely separate immunoassays that are specific for these compounds [27-30] or methods capable of their detection and specific identification such as liquid chromatography-tandem mass spectrometry (LC-MS/MS) [20, 31-33].

\section{Interpreting Drug Testing Results}

The interpretation of opioid testing results is far less straightforward than many health care providers who utilize this testing appreciate $[34,35]$. Detecting a wide array of opioid drugs with adequate sensitivity is a significant analytical challenge as already discussed. Metabolism that leads to conversion of one opioid drug to another clinically used drug further complicates the interpretation (Fig. 2). Understanding the nature of opioid metabolism and the strengths and limitations of opioid testing assays in the context of this metabolism is therefore essential to the effective use of these results, especially given the potential ramifications of the results.

Table 1 Detection of commonly prescribed opioids in three different commercially available opiate immunoassays using a $300 \mathrm{ng} / \mathrm{mL}$ cutoff concentration for morphine

\begin{tabular}{|c|c|c|c|}
\hline Drug & $\begin{array}{l}\text { Siemens (Syva) } \\
\text { EMIT }^{\mathrm{a}}\end{array}$ & $\begin{array}{l}\text { Microgenics } \\
\text { CEDIA }^{\mathrm{b}}\end{array}$ & $\begin{array}{l}\text { Abbott } \\
\text { FPIA }^{\mathrm{c}}\end{array}$ \\
\hline Buprenorphine & $>1,000,000$ & $>100,000$ & \\
\hline Codeine & $102-306$ & 300 & 237 \\
\hline Dihydrocodeine & 291 & 300 & 626 \\
\hline Fentanyl & $>1,000,000$ & $>100,000$ & \\
\hline Hydrocodone & 247 & 300 & 643 \\
\hline Hydromorphone & 498 & 300 & \\
\hline Levorphanol & 1,048 & 100,000 & 926 \\
\hline Meperidine & $>15,000$ & 150,000 & \\
\hline 6-Acetylmorphine & 435 & 300 & 746 \\
\hline Morphine-3-Glucuronide & 626 & 300 & 643 \\
\hline Nalorphine & 5,540 & 100,000 & \\
\hline Naloxone & 36,000 & 6,000 & \\
\hline Oxycodone & 1,500 & 10,000 & 2,857 \\
\hline Oxymorphone & 9,300 & 20,000 & 5,000 \\
\hline
\end{tabular}

${ }^{a}$ The concentration of opioid drug required to yield a positive test equivalent to $300 \mathrm{ng} / \mathrm{mL}$ of morphine based upon data available in the product insert for the test

${ }^{\mathrm{b}}$ The concentration of opioid drug that was tested and produced a positive test result using an assay calibrated to $300 \mathrm{ng} / \mathrm{mL}$ of morphine based upon data available in the product insert for the test

${ }^{\mathrm{c}}$ The estimated concentration of opioid drug required to produce a positive test result equivalent to $300 \mathrm{ng} / \mathrm{mL}$ of morphine based upon reported assay cross-reactivity of the immunoassay; however, these estimates assume linearity of the analytical assay within the concentration range tested [8]

\section{Morphine}

A prototype drug of the phenanthrene class of structurally related opioids, morphine is used clinically in a variety of immediate and extended release products. It undergoes extensive phase II metabolism via glucuronidation as its major pathway of elimination [36]. Alternative modes of metabolism via cytochrome P450 (CYP) enzymes have also been described. While these alternative elimination pathways are minor compared with glucuronidation, one of these pathways leads to conversion of small amounts of morphine into hydromorphone, an opioid drug that is used in clinical medicine as well as frequently sold illegally on the street [37-39]. The quantities of hydromorphone produced from morphine are small and $\sim 1 \%$ of the concentration of morphine. In the context of high-dose morphine treatment, these concentrations might exceed $1,000 \mathrm{ng} / \mathrm{mL}$, putting them into the range that one might find in an individual taking 1-2 mg dose of hydromorphone, which has significantly higher potency compared with morphine [23]. Morphine is also a product of codeine and heroin metabolism [36]. Distinguishing morphine use versus metabolic conversion is sometimes difficult. Detection of the heroin-specific metabolite, 6monoacetyl-morphine, while not always present especially at remote times relative to drug use, confirms the use of heroin [40]. The presence of morphine may also occur simply due to eating baked goods containing poppy seeds, which naturally contain small amounts of morphine and codeine [41]. Quantitative analysis may aid in the interpretation of urine drug screening results involving morphine and other drugs. Poppy seeds rarely yield urine morphine concentrations $>2,000 \mathrm{ng} / \mathrm{mL}$ [42]. Morphine or heroin abuse generally yields concentrations much higher [40]. The ratio of morphine to codeine can also be helpful in cases where both drugs are detected [43-46]. A ratio of morphine to codeine that is $>2: 1$ is consistent with heroin or poppy seed ingestion. Hydromorphone concentrations from metabolism of morphine rarely exceed $\sim 2 \%$ of the morphine concentration in urine [37]. Thus, higher concentrations relative to morphine would suggest use of hydromorphone rather than metabolic conversion from morphine.

\section{Codeine}

Codeine, another widely available prescription opioid drug, derives its primary analgesic effect through metabolic conversion to morphine via the action of the CYP450 enzyme, CYP2D6 [47, 48]. It is therefore expected that most patients taking codeine will have significant quantities of morphine in their urine; however, poor metabolizers may have significantly less or no detectable morphine. Although the majority of codeine is metabolized to morphine, a small quantity 
Fig. 1 Chemical structures of some commonly prescribed opioid drugs. Illustration of the structural differences between some of the commonly prescribed natural, semisynthetic, and synthetic opioid drugs. Gray boxes indicate the differences in structure compared with morphine that may affect detection by opiate immunoassays that are primarily directed towards natural opioids, morphine, and codeine, derived from poppy

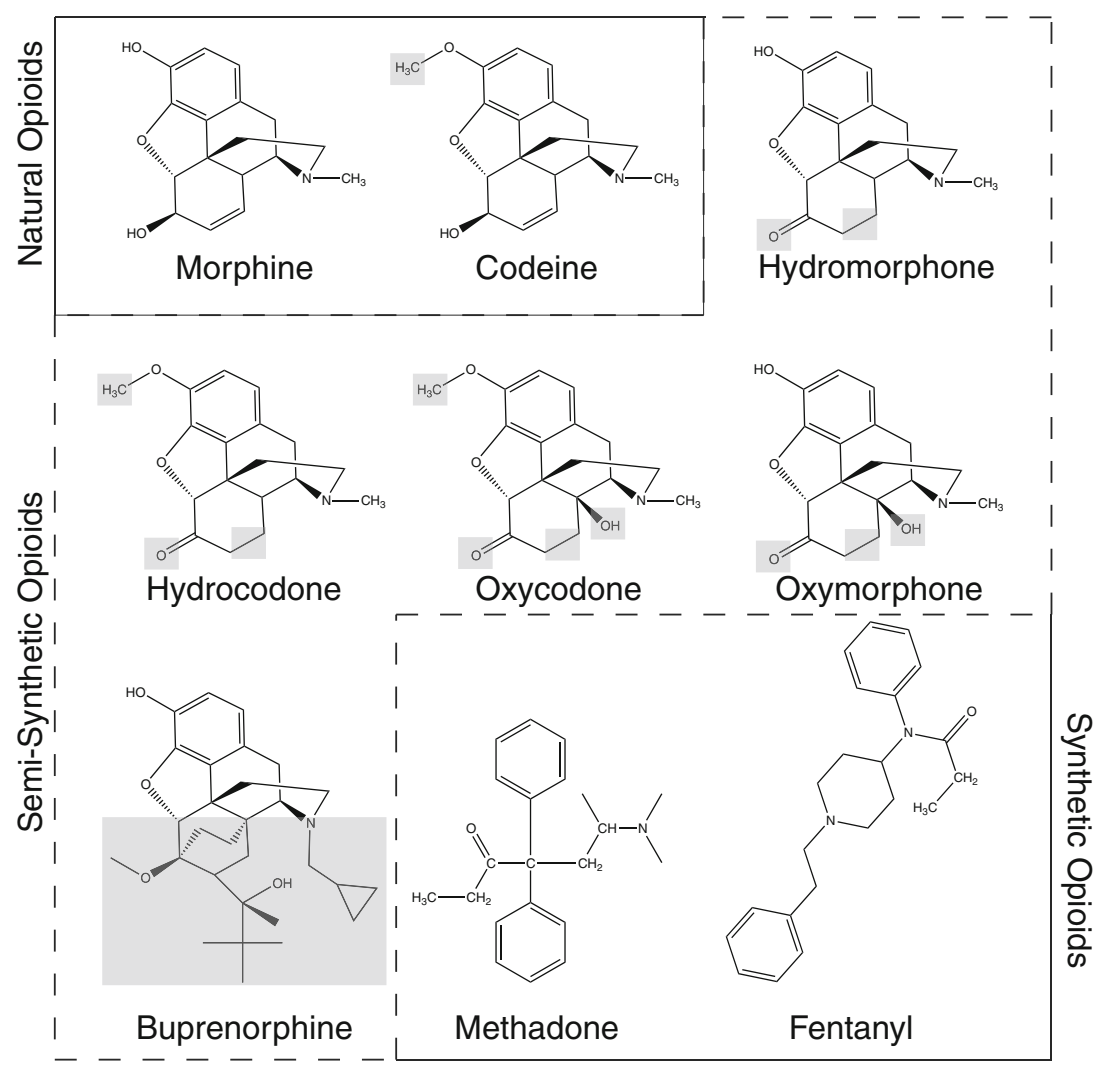

of codeine is also converted to hydrocodone with concentrations that can exceed $100 \mathrm{ng} / \mathrm{mL}$ with high doses [49]. The presence of codeine in the urine also does not always indicate the use of codeine-containing medications. A small quantity of codeine is present in poppy seeds along with morphine, and it may appear in the urine following consumption of poppy seeds $[41,42]$. It has also been observed in small quantities $(\sim 0.03 \%$ of the morphine concentration)

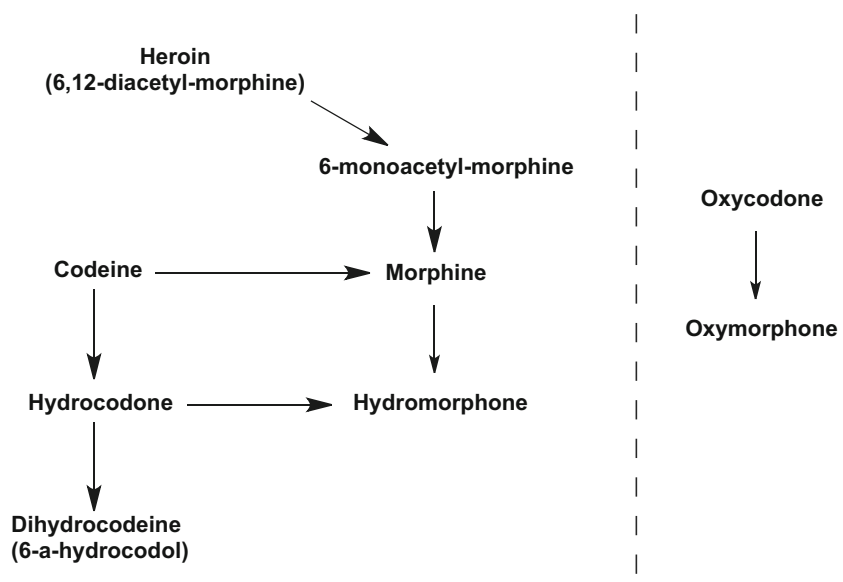

Fig. 2 Metabolic pathways for some commonly prescribed and illicit opioid drugs that affect the interpretation of drug testing. Illustration of known pathways for metabolic conversion of some commonly prescribed opioid drugs and heroin in patients on chronic morphine therapy [50]. Although difficult to confirm, the authors postulate that the source of codeine in these cases may derive from contamination of morphine with codeine sulfate derived during the manufacturing process as an impurity.

\section{Hydromorphone}

Hydromorphone is a high potency semisynthetic opioid drug with widespread use and abuse. Detection of hydromorphone varies across different opiate immunoassays with a reported range of $20-50 \%$ cross-reactivity at the typical $300 \mathrm{ng} / \mathrm{mL}$ cutoff concentration for morphine used by most clinical laboratories (see Table 1). This somewhat reduced cross-reactivity may lead to a shortened detection window following use of this drug. Metabolism of hydromorphone occurs almost exclusively via phase II glucuronidation to produce hydromorphone-3-glucuronide, an active metabolite [36]. No conversion to other opioid drugs has been reported. As described above, hydromorphone is a product of CYP450-mediated metabolism of morphine [37-39]. It is also a product of hydrocodone metabolism via CYP2D6 [51]. The concentrations of hydromorphone are generally less than hydrocodone (hydrocodone to hydromorphone ratio of $\sim 6-7$ ), but vary widely due to factors such as CYP2D6 genetics [52, 53]. 


\section{Hydrocodone}

Currently, the most widely abused prescription opioid drug in the USA, hydrocodone, is a semisynthetic opioid drugs exhibits variable detection using currently available opiate immunoassay screening tests. Some assays (e.g., Syva EMIT opiate assay) show almost equivalent detection to morphine, whereas others (e.g., Roche OnLine DAT opiate II assay) requiring 2-3-fold higher hydrocodone concentrations to yield a similar signal intensity to morphine at the $300 \mathrm{ng} / \mathrm{mL}$ cutoff concentration (see Table 1). The presence of hydrocodone in urine is also difficult to interpret. Hydrocodone undergoes CYP450mediated metabolism to produce both hydromorphone via CYP2D6 and norhydrocodone via CYP3A4 [36]. Additional minor metabolites that are detectable include 6 - $\alpha$-hydrocodol (also known as dihydrocodeine) and 6- $\beta$ hydrocodol [54]. Dihydrocodeine is an opioid drug marketed in a variety of pain and antitussive medications. Hydrocodone is also a minor metabolite of codeine as discussed above [49]. Quantitative analysis for hydrocodone, codeine, and norhydrocodone may help in determining the origin of hydrocodone [52, 55]. Since norhydrocodone is a major metabolite of hydrocodone only, the detection of this specific metabolite may be helpful in confirming hydrocodone use.

\section{Oxycodone and Oxymorphone}

Similar to hydrocodone, oxycodone, and oxymorphone, both semisynthetic 6-keto opioid drugs are poorly detected using commercially available opiate immunoassays. The Syva EMIT method requires approximately 5-fold higher concentrations of oxycodone to yield a similar signal intensity to morphine. The Roche OnLine DATA opiate assay shows extremely poor reactivity with oxycodone as well with no detection at concentrations more than 50-fold higher than morphine. As discussed previously, many cases of oxycodone use may be missed if testing is restricted to only a morphine-specific opiate assay. Most assay manufacturers now offer more specific oxycodone immunoassays to enhance the detection of this important opioid drug, and inclusion of an oxycodone-specific immunoassay is recommended to enhance the detection this prescription opioid. No metabolic conversion of illicit or prescription opioid drugs to oxycodone has been reported [36]; however, oxycodone does undergo phase I metabolism to oxymorphone, another opioid drug that was relatively recently introduced into the US market [56]. Fortunately, oxymorphone is well detected using the oxycodone-specific immunoassays, with almost $100 \%$ cross-reactivity reported in these assays [57].

\section{Fentanyl}

Fully synthetic opioids, fentanyl and related compounds, are not detected by commercial morphine- or oxycodone-specific opiate immunoassays [58]. Misuse and abuse of fentanyl with fatal consequences has increased in the past decade. Sources of fentanyl include diversion of pharmaceutical grade material, clandestine laboratories, and sustained-release, transdermal patches [59]. Cases of toxicity following ingestion of whole trans-dermal patches have even been reported [60]. Since fentanyl is an important prescription opioid with documented abuse potential, detection of this drug in urine screening is highly desirable. Although not routinely applied in many standard urine drug-testing panels, fentanyl-specific immunoassays have been developed [27, 61, 62]. A number of other analytical methods including gas chromatography-mass spectroscopy (GC-MS) [63-66] and LC-MS have also been described [67-70]. Some of these methods also include detection of fentanyl-like compounds in addition to fentanyl [32].

\section{Methadone}

Similar to fentanyl, methadone is a fully synthetic opioid without structural similarity to morphine or other semisynthetic opioid drugs. Frequently used in the treatment of opioid dependence and as a therapy for patients with chronic pain $[71,72]$, neither methadone or its primary metabolite, 2-ethylidene-1,5-dimethyl-3,3-diphenylpyrrolidine(EDDP) is detected by morphine-specific opiate immunoassay screening tests. Methadone-specific analysis techniques are therefore required for its detection, and immunoassays such as the DRI methadone assay (Microgenics Corp, Freemont, CA, USA) are commercially available for this opioid drug. Recently, tapentadol, a newer prescription analgesic, has been shown to react with the DRI methadone assay producing false positive results [73]. Although the cross-reactivity in the assay is low, it illustrates the need for confirmatory testing especially when the result does not fit with the clinical situation.

\section{Buprenorphine}

A synthetic opioid with partial agonist activity towards $\mu$ receptors, buprenorphine, like methadone, is used as both a treatment for opioid-dependent individuals as well as in chronic pain management [71, 74]. It is also not detected by morphine-specific opiate immunoassay screening tests (see Table 1). Immunoassay [30], GC-MS [75-77], and LC-MS [78-82] methods that are specific for buprenorphine are available and should be used when detection of this drug is required. 


\section{Sample Adulteration and Alternative Matrix Testing}

Urine is the traditional fluid used for drug testing due in part to the relatively simple collection. It is a fluid that is generally collected in private, and this fact offers the potential for specimen adulteration by dilution or addition of substances with the intent of interfering with testing to produce false negative results. Clinical settings often do not have the special restroom accommodations commonly available for workplace testing to minimize specimen manipulation. Despite these limitations, there are several tools available to aid in the detection of specimen adulteration (reviewed in [83]). Common methods of tampering such as specimen dilution with water can generally be detected by measurement of specific gravity and creatinine concentration to ensure that they are within a range that is physiologically possible. Testing for other adulterants such as oxidizers such as chromium and glutaraldehyde are also available. While some methods of adulteration are detectable, substitution of drugfree urine can be quite difficult to detect. Temperature measurements immediately following collection can be used to identify possible substitution; however, the determined individual can overcome this check. Even direct observation of collection can be circumvented by instillation of drug free urine into the bladder before testing. In addition, elaborate, anatomically correct prosthetic devices are available that can sometimes fool a naive collector during witnessed collections. Use of random testing can limit some of these adulteration methods, but the ability to test without the concern of specimen adulteration is highly desirable.

Significant effort has been expended to develop testing methods for alternative specimen types that permit simple, observed collection. One of the most promising specimens to potentially meet these requirements is saliva. Drug concentrations in oral fluid often parallel the free drug concentration in serum [84]. Due to the mildly acidic $\mathrm{pH}$ of saliva, basic drugs such as opioids may even show higher concentrations for longer periods of time following use compared to blood due to an "ion trapping" effect of weakly basic drugs like morphine within mildly acidic saliva [84, 86]. This advantage is suggested by the high frequency of detecting 6-monoacetyl-morphine with morphine in oral fluid compared with typical frequencies in urine of patients using heroin $[87,88]$. One of the major challenges for oral fluid analysis is the generally small specimen size and consistent collection [89], which limits the ability to perform multidrug testing and especially limits the definitive identification of drugs following positive screening tests. This is often compounded by the mouth dryness that accompanies use of many drugs including opioids [90].

Beyond oral fluid, other sample matrices may be used in drug analysis including sweat and hair. Both methods are noninvasive and offer the potential to detect opioid drugs
[91, 92]. Patch devices for sweat collection are commercially available and permit collection of sweat over a 1-week period, which potentially extends the detection window for drug detection beyond the relatively short period possible with oral fluid or urine [83]. While an attractive alternative, application of sweat testing in clinical treatment settings suggest that patch collection of sweat is poorly accepted and less sensitive than frequent urine testing for opioid detection [93, 94]. The reduced sensitivity may in part be due to differences in drug distribution to sweat, which seems to be good for some opioids such as heroin and codeine but poorer for morphine [92, 95]. Hair analysis has the potential advantage of permitting detection of drug use over much longer periods that are on the order of weeks to months translating into greater detection of aberrant drug use compared with urine testing [96, 97]. In order to test hair, extraction of drug from the matrix is required prior to analysis. The possibility of contamination from environmental exposure is a greater possibility compared with urine [98].

\section{Conclusion}

Drug testing for opioid drugs is an important tool that health care providers can use to assess opioid treatment compliance and opioid misuse; however, no diagnostic test is perfect. UDT is certainly not capable of identifying all cases of opioid use or misuse. Determining the accuracy of UDT is difficult as it is often used as a gold standard by which other methods of risk assessment or misuse detection are gauged. In a study of chronic pain patients, $88 \%$ of patients who reported use were positive for an opioid on UDT; however, this study also demonstrated that many patients fail to report their drug use, especially illicit drugs [99].

The ideal approach to testing will likely depend greatly upon the scenario in which the testing is used. In the clinical setting, particularly where urgent decisions must often be made, clinicians will generally only have unconfirmed immunoassay screening results since it can take $24 \mathrm{~h}$ or more to complete confirmatory testing depending upon the laboratory's testing work flow. In the pain medicine realm, which is a rapidly expanding area of drug testing, the ideal approach to testing is also largely unknown. Some have advocated random, sporadic testing of high risk patients while others advocate universal testing of patients every visit $[11,99]$. Neither approach has been evaluated in prospective clinical trials. This area of testing is an important area in need of much more outcome-based research. It is quite possible that UDT may show its best 
efficiency when combined with other screening tools such as behavioral assessment tools.

\section{References}

1. Stang P, Von Korff M, Galer BS (1998) Reduced labor force participation among primary care patients with headache. J Gen Intern Med 13(5):296-302, Epub 1998/06/05

2. Volkow ND, McLellan TA, Cotto JH, Karithanom M, Weiss SR (2011) Characteristics of opioid prescriptions in 2009. JAMA: J Am Med Assoc 305(13):1299-1301, Epub 2011/04/07

3. Manchikanti L, Helm Ii S, Fellows B, Janata JW, Pampati V, Grider JS et al (2012) Opioid epidemic in the United States. Pain Physician 15(3 Suppl), ES9- ES38. Epub 2012/07/20

4. Okie S (2010) A flood of opioids, a rising tide of deaths. N Engl J Med 363(21):1981-1985, Epub 2010/11/19

5. Akbik H, Butler SF, Budman SH, Fernandez K, Katz NP, Jamison RN (2006) Validation and clinical application of the Screener and Opioid Assessment for Patients with Pain (SOAPP). J Pain Symptom Manag 32(3):287-293, Epub 2006/08/31

6. Butler SF, Budman SH, Fernandez K, Jamison RN (2004) Validation of a screener and opioid assessment measure for patients with chronic pain. Pain 112(1-2):65-75, Epub 2004/10/21

7. Webster LR, Webster RM (2005) Predicting aberrant behaviors in opioid-treated patients: preliminary validation of the Opioid Risk Tool. Pain Med 6(6):432-442, Epub 2005/12/13

8. Yudko E, Lozhkina O, Fouts A (2007) A comprehensive review of the psychometric properties of the drug abuse screening test. J Subst Abus Treat 32(2):189-198, Epub 2007/02/20

9. Butler SF, Budman SH, Fernandez KC, Houle B, Benoit C, Katz N et al (2007) Development and validation of the current opioid misuse measure. Pain 130(1-2):144-156, Epub 2007/05/12

10. Gugelmann HM, Perrone J (2011) Can prescription drug monitoring programs help limit opioid abuse. JAMA: J Am Med Assoc 306(20):2258-2259, Epub 2011/11/24

11. Chou R, Fanciullo GJ, Fine PG, Adler JA, Ballantyne JC, Davies P et al (2009) Clinical guidelines for the use of chronic opioid therapy in chronic noncancer pain. J Pain: Off J Am Pain Soc 10 (2):113-130. doi:113, Epub 2009/02/04

12. Notice changing the opiate testing cutoff concentrations (1998) Federal Register: United States Department of Health and Human Services p. 29916

13. Clinical and Laboratory Standards Institute (2005) Clinical and Laboratory Standards Institute: Toxicology and Drug Testing in the Clinical Laboratory; Approved Guideline, 2nd edn. Clinical and Laboratory Standards Institute, Wayne, pp 1-51

14. Anglin D, Westland CA (1989) Drug monitoring in the workplace: Results from the California commercial laboratory drug testing project. 1989

15. Heltsley R, Zichterman A, Black DL, Cawthon B, Robert T, Moser $F$ et al (2010) Urine drug testing of chronic pain patients. II. Prevalence patterns of prescription opiates and metabolites. J Anal Toxicol 34(1):32-38, Epub 2010/01/30

16. Reisfield GM, Salazar E, Bertholf RL (2007) Rational use and interpretation of urine drug testing in chronic opioid therapy. Ann Clin Lab Sci 37(4):301-314, Epub 2007/11/15

17. Luzzi VI, Saunders AN, Koenig JW, Turk J, Lo SF, Garg UC et al (2004) Analytic performance of immunoassays for drugs of abuse below established cutoff values. Clin Chem 50(4):717-722, Epub 2004/02/07

18. Pesce A, West C, West R, Crews B, Mikel C, Rosenthal M et al (2011) Determination of medication cutoff values in a pain patient population. J Opioid Manag 7(2):117-122, Epub 2011/05/13
19. Baden LR, Horowitz G, Jacoby H, Eliopoulos GM (2001) Quinolones and falsepositive urine screening for opiates by immunoassay technology. JAMA: J Am Med Assoc 286(24):3115-3119, Epub 2002/01/05

20. Smith ML, Shimomura ET, Summers J, Paul BD, Nichols D, Shippee R et al (2000) Detection times and analytical performance of commercial urine opiate immunoassays following heroin administration. J Anal Toxicol 24(7):522-529, Epub 2000/10/24

21. Cook JD (2011) Minutes from the SAMHSA center for substance abuse prevention drug testing advisory board meeting, July 12-13 . In: SAMHSA, editor. Accessed August 20, 20122011

22. Levine B (2010)Principles of forensic toxicology. 3rd ed. Washington, DC: American Association for Clinical Chemistry; viii, 471 p. p

23. Smith ML, Hughes RO, Levine B, Dickerson S, Darwin WD, Cone EJ (1995) Forensic drug testing for opiates. VI. Urine testing for hydromorphone, hydrocodone, oxymorphone, and oxycodone with commercial opiate immunoassays and gas chromatography-mass spectrometry. J Anal Toxicol 19(1):1826, Epub 1995/01/01

24. Levy S, Sherritt L, Vaughan BL, Germak M, Knight JR (2007) Results of random drug testing in an adolescent substance abuse program. Pediatrics 119(4):e843-e848, Epub 2007/04/04

25. Melanson SE, Baskin L, Magnani B, Kwong TC, Dizon A, Wu AH (2010) Interpretation and utility of drug of abuse immunoassays: lessons from laboratory drug testing surveys. Arch Pathol Lab Med 134(5):735-739, Epub 2010/05/06

26. Gingras M, Laberge MH, Lefebvre M (2010) Evaluation of the usefulness of an oxycodone immunoassay in combination with a traditional opiate immunoassay for the screening of opiates in urine. J Anal Toxicol 34(2):78-83, Epub 2010/03/13

27. Wang G, Huynh K, Barhate R, Rodrigues W, Moore C, Coulter C et al (2011) Development of a homogeneous immunoassay for the detection of fentanyl in urine. Forensic Sci Int 206(1-3):127-131, Epub 2010/08/31

28. Melanson SE, Snyder ML, Jarolim P, Flood JG (2012) A new highly specific buprenorphine immunoassay for monitoring buprenorphine compliance and abuse. J Anal Toxicol 36(3):201-206, Epub 2012/03/16

29. Leino A, Loo BM (2007) Comparison of three commercial tests for buprenorphine screening in urine. Ann Clin Biochem 44(Pt 6):563-565, Epub 2007/10/27

30. Bottcher M, Beck O (2005) Evaluation of buprenorphine CEDIA assay versus GC-MS and ELISA using urine samples from patients in substitution treatment. J Anal Toxicol 29(8):769-776, Epub $2005 / 12 / 17$

31. Kronstrand R, Selden TG, Josefsson M (2003) Analysis of buprenorphine, norbuprenorphine, and their glucuronides in urine by liquid chromatographymass spectrometry. J Anal Toxicol 27 (7):464-470, Epub 2003/11/11

32. Cooreman S, Deprez C, Martens F, Van Bocxlaer J, Croes K (2010) A comprehensive LC-MS-based quantitative analysis of fentanyl-like drugs in plasma and urine. J Sep Sci 33(1718):2654-2662, Epub 2010/07/27

33. Huynh NH, Tyrefors N, Ekman L, Johansson M (2005) Determination of fentanyl in human plasma and fentanyl and norfentanyl in human urine using LC-MS/MS. J Pharm Biomed Anal 37 (5):1095-1100, Epub 2005/05/03

34. Starrels JL, Fox AD, Kunins HV, Cunningham CO (2012) They don't know what they don't know: internal medicine residents' knowledge and confidence in urine drug test interpretation for patients with chronic pain. J Gen Intern Med. Epub 2012/07/21

35. Levy S, Harris SK, Sherritt L, Angulo M, Knight JR (2006) Drug testing of adolescents in ambulatory medicine: physician practices and knowledge. Arch Pediatr Adolesc Med 160(2):146-150, Epub 2006/02/08 
36. Smith HS (2009) Opioid metabolism. Mayo Clin Proc 84(7):613624, Epub 2009/07/02

37. Cone EJ, Caplan YH, Moser F, Robert T, Black D (2008) Evidence that morphine is metabolized to hydromorphone but not to oxymorphone. J Anal Toxicol 32(4):319-323, Epub 2008/04/24

38. Reisfield GM, Chronister CW, Goldberger BA, Bertholf RL (2009) Unexpected urine drug testing results in a hospice patient on highdose morphine therapy. Clin Chem 55(10):1765-1768, Epub 2009/ $09 / 30$

39. Wasan AD, Michna E, Janfaza D, Greenfield S, Teter CJ, Jamison $\mathrm{RN}$ (2008) Interpreting urine drug tests: prevalence of morphine metabolism to hydromorphone in chronic pain patients treated with morphine. Pain Med 9(7):918-923, Epub 2008/07/12

40. Smith ML, Shimomura ET, Summers J, Paul BD, Jenkins AJ, Darwin WD et al (2001) Urinary excretion profiles for total morphine, free morphine, and 6- acetylmorphine following smoked and intravenous heroin. J Anal Toxicol 25(7):504-514, Epub 2001/10/16

41. Pelders MG, Ros JJ (1996) Poppy seeds: differences in morphine and codeine content and variation in inter- and intra-individual excretion. J Forensic Sci 41(2):209-212, Epub 1996/03/01

42. Selavka CM (1991) Poppy seed ingestion as a contributing factor to opiatepositive urinalysis results: the Pacific perspective. J Forensic Sci 36(3):685-696, Epub 1991/05/01

43. Ceder G, Jones AW (2001) Concentration ratios of morphine to codeine in blood of impaired drivers as evidence of heroin use and not medication with codeine. Clin Chem 47(11):1980-1984, Epub 2001/10/24

44. Moriya F, Chan KM, Hashimoto Y (1999) Concentrations of morphine and codeine in urine of heroin abusers. Leg Med (Tokyo) 1(3):140-144, Epub 2003/08/26

45. Jones AW, Holmgren A, Kugelberg FC (2008) Driving under the influence of opiates: concentration relationships between morphine, codeine, 6-acetyl morphine, and ethyl morphine in blood. J Anal Toxicol 32(4):265-272, Epub 2008/04/24

46. Konstantinova SV, Normann PT, Arnestad M, Karinen R, Christophersen AS, Morland J (2012) Morphine to codeine concentration ratio in blood and urine as a marker of illicit heroin use in forensic autopsy samples. Forensic Sci Int 217(1-3):216-221, Epub 2011/ $12 / 06$

47. Lotsch J (2005) Opioid metabolites. J Pain Symptom Manag 29(5 Suppl):S10-S24, Epub 2005/05/24

48. Desmeules J, Gascon MP, Dayer P, Magistris M (1991) Impact of environmental and genetic factors on codeine analgesia. Eur J Clin Pharmacol 41(1):23-26, Epub 1991/01/01

49. Oyler JM, Cone EJ, Joseph RE Jr, Huestis MA (2000) Identification of hydrocodone in human urine following controlled codeine administration. J Anal Toxicol 24(7):530-535, Epub 2000/10/24

50. West R, Crews B, Mikel C, Almazan P, Latyshev S, Pesce A et al (2009) Anomalous observations of codeine in patients on morphine. Ther Drug Monit 31(6):776-778, Epub 2009/11/26

51. Hutchinson MR, Menelaou A, Foster DJ, Coller JK, Somogyi AA (2004) CYP2D6 and CYP3A4 involvement in the primary oxidative metabolism of hydrocodone by human liver microsomes. Br J Clin Pharmacol 57(3):287-297, Epub 2004/03/05

52. Valtier S, Bebarta VS (2012) Excretion profile of hydrocodone, hydromorphone and norhydrocodone in urine following single dose administration of hydrocodone to healthy volunteers. J Anal Toxicol. Epub 2012/07/12

53. Barakat NH, Atayee RS, Best BM, Pesce AJ (2012) Relationship between the concentration of hydrocodone and its conversion to hydromorphone in chronic pain patients using urinary excretion data. J Anal Toxicol 36(4):257-264, Epub 2012/04/19

54. Jenkins AJ, Lavins ES, Hunek C (2009) Prevalence of dihydrocodeine in hydrocodone positive postmortem specimens. J Forensic Psychiatr 16(2):64-66, Epub 2009/01/13
55. Cone EJ, Zichterman A, Heltsley R, Black DL, Cawthon B, Robert $\mathrm{T}$ et al (2010) Urine testing for norcodeine, norhydrocodone, and noroxycodone facilitates interpretation and reduces false negatives. Forensic Sci Int 198(1-3):58-61, Epub 2009/12/29

56. Gimbel JS (2008) Oxymorphone: a mature molecule with new life. Drugs Today (Barc) 44(10):767-782, Epub 2009/01/13

57. Backer RC, Monforte JR, Poklis A (2005) Evaluation of the DRI oxycodone immunoassay for the detection of oxycodone in urine. $\mathrm{J}$ Anal Toxicol 29(7):675-677, Epub 2006/01/20

58. Poklis A (1995) Fentanyl: a review for clinical and analytical toxicologists. J Toxicol Clin Toxicol 33(5):439-447, Epub 1995/ $01 / 01$

59. Krinsky CS, Lathrop SL, Crossey M, Baker G, Zumwalt R (2011) A toxicologybased review of fentanyl-related deaths in New Mexico (1986-2007). The Am J Forensic Med Pathol 32(4):347-351, Epub 2011/10/12

60. Mrvos R, Feuchter AC, Katz KD, Duback-Morris LF, Brooks DE, Krenzelok EP (2012) Whole fentanyl patch ingestion: a multicenter case series. Can J Emerg Med 42(5):549-552, Epub 2011/ $06 / 21$

61. Poklis A, Backer R (2004) Urine concentrations of fentanyl and norfentanyl during application of Duragesic transdermal patches. $\mathrm{J}$ Anal Toxicol 28(6):422-425, Epub 2004/11/02

62. Mao CL, Zientek KD, Colahan PT, Kuo MY, Liu CH, Lee KM et al (2006) Development of an enzyme-linked immunosorbent assay for fentanyl and applications of fentanyl antibody-coated nanoparticles for sample preparation. J Pharm Biomed Anal 41 (4):1332-1341, Epub 2006/04/20

63. Gillespie TJ, Gandolfi AJ, Maiorino RM, Vaughan RW (1981) Gas chromatographic determination of fentanyl and its analogues in human plasma. J Anal Toxicol 5(3):133-137, Epub 1981/05/01

64. Bentley JB, Borel JD, Nenad RE Jr, Gillespie TJ (1982) Age and fentanyl pharmacokinetics. Anesth Analg 61(12):968-971, Epub 1982/12/01

65. Van Rooy HH, Vermeulen MP, Bovill JG (1981) The assay of fentanyl and its metabolites in plasma of patients using gas chromatography with alkali flame ionisation detection and gas chromatography-mass spectrometry. J Chromatogr 223(1):85-93, Epub 1981/04/10

66. Strano-Rossi S, Alvarez I, Tabernero MJ, Cabarcos P, Fernandez P, Bermejo AM (2011) Determination of fentanyl, metabolite and analogs in urine by GC/MS. J Appl Toxicol: JAT 31(7):649-654, Epub 2010/12/07

67. Coopman V, Cordonnier J, Pien K, Van Varenbergh D (2007) LCMS/MS analysis of fentanyl and norfentanyl in a fatality due to application of multiple Durogesic transdermal therapeutic systems. Forensic Sci Int 169(2-3):223-227, Epub 2006/05/03

68. Peer CJ, Shakleya DM, Younis IR, Kraner JC, Callery PS (2007) Direct-injection mass spectrometric method for the rapid identification of fentanyl and norfentanyl in postmortem urine of six drugoverdose cases. J Anal Toxicol 31(8):515-521, Epub 2007/11/09

69. Bagheri H, Es-haghi A, Khalilian F, Rouini MR (2007) Determination of fentanyl in human plasma by head-space solid-phase microextraction and gas chromatography-mass spectrometry. J Pharm Biomed Anal 43(5):1763-1768, Epub 2007/01/26

70. Thevis M, Geyer H, Bahr D, Schanzer W (2005) Identification of fentanyl, alfentanil, sufentanil, remifentanil and their major metabolites in human urine by liquid chromatography/tandem mass spectrometry for doping control purposes. Eur J Mass Spectrom (Chichester, Eng) 11(4):419-427, Epub 2005/10/06

71. Tetrault JM, Fiellin DA (2012) Current and potential pharmacological treatment options for maintenance therapy in opioid-dependent individuals. Drugs 72(2):217-228, Epub 2012/01/13

72. Martin CM (2011) Methadone: marvelous, malevolent, or merely misunderstood. Consult Pharm: J Am Soc Consult Pharmacists 26 (1):32-40, Epub 2011/01/13 
73. Collins AA, Merritt AP, Bourland JA (2012) Cross-reactivity of tapentadol specimens with DRI Methadone Enzyme Immunoassay. J Anal Toxicol. Epub 2012/08/11

74. Davis MP (2012) Twelve reasons for considering buprenorphine as a frontline analgesic in the management of pain. J Support Oncol. Epub 2012/07/20

75. Gopal S, Tzeng TB, Cowan A (2001) Development and validation of a sensitive analytical method for the simultaneous determination of buprenorphine and norbuprenorphine in human plasma. Eur J Pharm Biopharm: Off J Arbeitsgemeinschaft fur Pharmazeutische Verfahrenstechnik eV 51(2):147-151, Epub 2001/02/28

76. George S, George C, Chauhan M (2004) The development and application of a rapid gas chromatography-mass spectrometry method to monitor buprenorphine withdrawal protocols. Forensic Sci Int 143(2-3):121-125, Epub 2004/07/09

77. Fuller DC (2008) A simple gas chromatography-mass spectrometry procedure for the simultaneous determination of buprenorphine and norbuprenorphine in human urine. J Anal Toxicol 32(8):626630, Epub 2008/11/15

78. Hull MJ, Bierer MF, Griggs DA, Long WH, Nixon AL, Flood JG (2008) Urinary buprenorphine concentrations in patients treated with suboxone as determined by liquid chromatography-mass spectrometry and CEDIA immunoassay. J Anal Toxicol 32 (7):516-521, Epub 2008/08/21

79. Twigger S, Fox E, Allen K (2008) Measurement of buprenorphine in urine: immunoassay versus LC-MS/MS. Ann Clin Biochem 45 (Pt 3):339, Epub 2008/05/17

80. Hegstad S, Khiabani HZ, Oiestad EL, Berg T, Christophersen AS (2007) Rapid quantification of buprenorphine-glucuronide and norbuprenorphine-glucuronide in human urine by LC-MS-MS. J Anal Toxicol 31(4):214-219, Epub 2007/06/09

81. Rodriguez-Rosas ME, Lofwall MR, Strain EC, Siluk D, Wainer IW (2007) Simultaneous determination of buprenorphine, norbuprenorphine and the enantiomers of methadone and its metabolite (EDDP) in human plasma by liquid chromatography/mass spectrometry. J Chromatogr B, Anal Technol Biomed Life Sci 850(12):538-543, Epub 2006/12/05

82. McMillin GA, Davis R, Carlisle H, Clark C, Marin SJ, Moody DE (2012) Patterns of free (unconjugated) buprenorphine, norbuprenorphine, and their glucuronides in urine using liquid chromatography-tandem mass spectrometry. J Anal Toxicol 36(2):81-87, Epub 2012/02/18

83. Sutheimer CA, Cody JT (2009) Subversion of Regulated Workplace Drug Testing - Specimen Adulteration and Substitution. In: Ropero-Miller JD, Goldberger BA, Liu RH (eds) Handbook of workplace drug testing, 2nd edn. American Association for Clinical Chemistry, Washington, DC, pp 121-155

84. Jenkins AJ, Oyler JM, Cone EJ (1995) Comparison of heroin and cocaine concentrations in saliva with concentrations in blood and plasma. J Anal Toxicol 19(6):359-374, Epub 1995/10/01
85. Bosker WM, Huestic MA (2009) Oral fluid testing for drugs of abuse. Clinical chemistry 55(11):1910-1931, Epub 2009/09/12

86. Cone EJ, Clarke J, Tsanaclis L (2007) Prevalence and disposition of drugs of abuse and opioid treatment drugs in oral fluid. J Anal Toxicol 31(8):424-433, Epub 2007/11/09

87. Presley L, Lehrer M, Seiter W, Hahn D, Rowland B, Smith M et al (2003) High prevalence of 6-acetylmorphine in morphine-positive oral fluid specimens. Forensic Sci Int 133(1-2):22-25, Epub 2003/ $05 / 14$

88. Crouch DJ, Walsh JM, Flegel R, Cangianelli L, Baudys J, Atkins R (2005) An evaluation of selected oral fluid point-of-collection drug-testing devices. J Anal Toxicol 29(4):244-248, Epub 2005/ $06 / 25$

89. White ID, Hoskin PJ, Hanks GW, Bliss JM (1989) Morphine and dryness of the mouth. BMJ 298(6682):1222-1223, Epub 1989/05/06

90. Moore C, Feldman M, Harrison E, Rana S, Coulter C, Kuntz D et al (2006) Disposition of hydrocodone in hair. J Anal Toxicol 30 (6):353-359, Epub 2006/07/29

91. Kintz P, Brenneisen R, Bundeli P, Mangin P (1997) Sweat testing for heroin and metabolites in a heroin maintenance program. Clin Chem Epub 1997/05/01(5):736-739, Epub 1997/05/01

92. Chawarski MC, Fiellin DA, O'Connor PG, Bernard M, Schottenfeld RS (2007) Utility of sweat patch testing for drug use monitoring in outpatient treatment for opiate dependence. J Subst Abus Treat 33(4):411-415, Epub 2007/05/22

93. Huestis MA, Cone EJ, Wong CJ, Umbricht A, Preston KL (2000) Monitoring opiate use in substance abuse treatment patients with sweat and urine drug testing. J Anal Toxicol 24(7):509-521, Epub 2000/10/24

94. Schwilke EW, Barnes AJ, Kacinko SL, Cone EJ, Moolchan ET, Huestis MA (2006) Opioid disposition in human sweat after controlled oral codeine administration. Clin Chem 52(8):1539-1545, Epub 2006/06/03

95. Haller DL, Acosta MC, Lewis D, Miles DR, Schiano T, Shapiro PA et al (2010) Hair analysis versus conventional methods of drug testing in substance abusers seeking organ transplantation. Am J Transplant: Off J Am Soc Transplant Am Soc Transplant Surg 10 (5):1305-1311, Epub 2010/04/01

96. Musshoff F, Driever F, Lachenmeier K, Lachenmeier DW, Banger M, Madea B (2006) Results of hair analyses for drugs of abuse and comparison with selfreports and urine tests. Forensic Sci Int 156(23):118-123, Epub 2006/01/18

97. Romano G, Barbera N, Lombardo I (2001) Hair testing for drugs of abuse: evaluation of external cocaine contamination and risk of false positives. Forensic Sci Int 123(2-3):119-129, Epub 2001/12/01

98. Fishbain DA, Cutler RB, Rosomoff HL, Rosomoff RS (1999) Validity of selfreported drug use in chronic pain patients. Clin J Pain 15(3):184-91

99. Cone EJ, Caplan YH (2009) Urine toxicology testing in chronic pain management. Postgrad Med 121(4):91-102, Epub 2009/07/31 